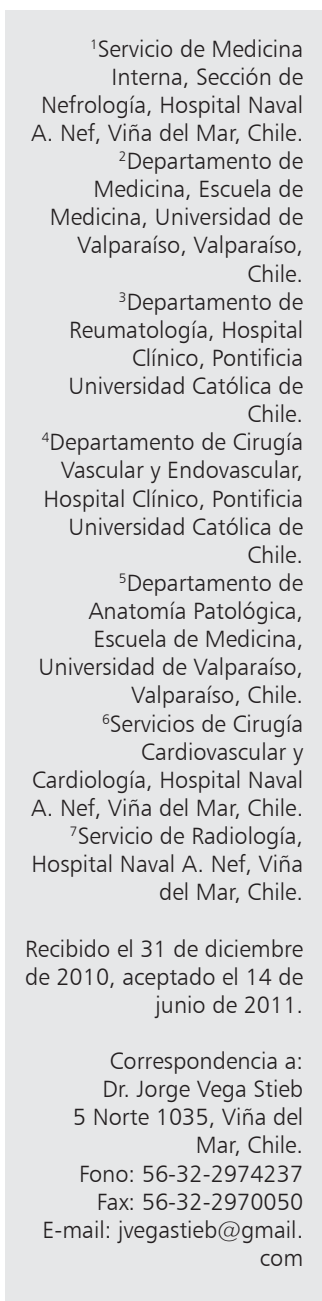

\section{Enfermedad de Erdheim-Chester. Una causa rara de derrame pericárdico. Caso clínico}

\author{
JORGE VEGA ${ }^{1,2}$, MARCELA CISTERNAS ${ }^{3}$, \\ MICHEL BERGOEING ${ }^{4}$, ROBERTO ESPINOSA ${ }^{5}$, ALVARO ZAPICO ${ }^{6}$, \\ PEDRO CHADID $^{6}$, MARIO SANTAMARINA ${ }^{7}$
}

\section{Erdheim-Chester disease. Report of one case}

We report a 76-year-old male who was admitted due to progressive congestive heart failure lasting several months. An echocardiogram showed a large pericardial effusion with early signs of pericardial tamponade and an irregular surface suggestive of cancer infiltration. The patient was operated, creating a pericardial window and draining 1,200 $\mathrm{ml}$ of a brownish yellow fluid with abundant cellularity. Pericardial biopsy showed infiltration by CD68 (+), CD1a (-) and S100 (-) cells. Twenty-eight months earlier, due to fatigue, dyspnea, and a non-specific inflammatory process, an enhanced-contrast-scan showed that aorta was coated with a hypodense tissue that began near the aortic valve and extended until the inferior mesenteric artery, with stenosis of the left subclavian, celiac axis, renal and upper mesenteric arteries. An angioplasty and stent placing was carried out in the last two arteries. Both kidneys had the appearance of "hairy kidneys". A bone scan showed increased uptake in femurs and tibiae and X-ray examination showed osteosclerosis in metaphysis and diaphysis. The diagnosis of Erdheim-Chester disease (non-Langerhans-cell histiocytosis) was made and the patient was treated with steroids and methotrexate.

(Rev Med Chile 2011; 139: 1054-1059).

Key words: Erdheim-Chester disease; Cardiac tamponade; Histiocytosis, nonLangerhans; Pericardial effusion.
L a enfermedad de Erdheim-Chester (ECD) es una forma de histiocitosis de células no $\checkmark$ Langerhans que infiltra en forma simétrica las metáfisis y diáfisis de fémures y tibias en forma patognomónica ${ }^{1,2}$. Las radiografías muestran osteoesclerosis y el cintigrama óseo con Tecnecio ${ }^{99}$ o con Galio un aumento de captación simétrico en dichas zonas ${ }^{2}$. Puede comprometer con menor frecuencia: cráneo, columna vertebral, cara, pelvis y extremidades superiores ${ }^{3}$. Esta enfermedad puede afectar en la mitad de los pacientes órganos extra-esqueléticos como sistema nervioso central, eje hipotálamo-hipofisiario, globo ocular y órbita, tiroides, laringe, aorta y sus ramas, hígado y vías biliares, riñones, glándulas suprarrenales, mamas, testículos, ganglios linfáticos, piel, pleura, pulmones y corazón ${ }^{1,4,5}$. Su frecuencia es escasa, hasta el año 2010 sólo se habían comunicado 320 casos, con una leve preponderancia en varones y una edad promedio de 54,7 años (rango: 16-77 años) $)^{1,4,6}$.

Comunicamos el caso de un paciente que presentó un derrame pericárdico con signos iniciales de taponamiento cardiaco secundario a esta enfermedad, 28 meses después del diagnóstico clínico de ECD.

\section{Caso clínico}

Hombre de 73 años con antecedentes de hipertensión arterial en tratamiento con valsartán e hidroclorotiazida y trombocitemia esencial 
bajo terapia inicialmente con hidroxiurea y luego anagrelide.

A mediados de diciembre de 2007 consultó porque desde hacía 8 meses presentaba fatigabilidad, astenia, adinamia, sudoración nocturna, disnea de esfuerzo y tos seca frecuente no productiva. No había tenido fiebre, baja de peso ni prurito. El electrocardiograma y radiografía de tórax fueron normales, salvo elongación aórtica moderada y el ecocardiograma mostró insuficiencia aórtica leve, aurícula y ventrículo izquierdo de tamaño y función conservada. En el hemograma destacaba hematocrito de $29 \%$, macrocitosis, rouleaux ++ , VHS $49 \mathrm{~mm}$ /hora y plaquetas de $717.000 \mathrm{~mm}^{3}$. Los exámenes generales fueron normales (Tabla 1 ). Una semana después presentó esputo hemoptoico y fue hospitalizado por sospecha de embolia pulmonar. Se realizó un AngioTAC de tórax que descartó trombos pero mostró que la pared de la aorta ascendente, sobre el plano valvular aórtico, estaba cubierta por un tejido hipodenso, que se extendía por la aorta abdominal hasta la arteria mesentérica inferior (Figura 1). También presentaban un halo similar las arterias subclavia izquierda, renales y mesentérica superior (AMS). Las arterias renales y mesentéricas estaban estenosadas, el tronco celíaco presentaba dilatación post-estenótica y el flujo sanguíneo por la AMS era filiforme. Existía un leve derrame pericárdico, esplenomegalia de $15 \mathrm{~cm}$ y edema perinéfrico bilateral. El cintigrama renal mostró disminución de la perfusión y función del riñón izquierdo (RD 62\%, RI 38\%). Los

Tabla 1. Exámenes de laboratorio durante la evolución de la enfermedad

\begin{tabular}{|c|c|c|c|c|c|}
\hline & Al diagnóstico & 3 meses & 12 meses & 28 meses & 30 meses \\
\hline Hematocrito (\%) & 31,8 & 30,5 & 31,2 & 30,4 & 34,0 \\
\hline Hemoglobina (g/dl) & 9,8 & 10,6 & 10,0 & 9,9 & 10,1 \\
\hline Leucocitos $\left(\mathrm{mm}^{3}\right)$ & 8.300 & 12.800 & 14.100 & 14.700 & 15.900 \\
\hline Plaquetas $\left(\mathrm{mm}^{3}\right)$ & 526.000 & 273.000 & 257.000 & 251.000 & 520.000 \\
\hline VHS (mm/hora) & 59 & 91 & 40 & 27 & 28 \\
\hline Frotis sanguíneo & Rouleaux ++ & Rouleaux ++ & & & Rouleaux + \\
\hline VCM (fL) & 105.6 & 95,4 & & & \\
\hline Creatininemia (mg/dl) & 1,14 & 1,42 & 1,43 & 1,56 & 1,29 \\
\hline Uremia (mg/dl) & 44 & 46 & 49 & 66,3 & 53 \\
\hline Uricemia (mg/dl) & & 7,6 & 8,1 & 12,4 & 7,4 \\
\hline Proteinemia (g/dl) & & 5,5 & 5,6 & & 6,2 \\
\hline Albuminemia (g/dl) & & 3,0 & 3,4 & & 3,4 \\
\hline SGOT (U/L) (5-18) & 7 & 16 & 10 & & \\
\hline SGPT (U/L) (5-22) & 6 & & & & \\
\hline GGT (U/L) (8-61) & 16 & & & & \\
\hline Fosfatasas alc.(U/L) (45-115) & 61 & 49 & 46 & & 52 \\
\hline LDH (U/L) (135-225) & & 290 & 257 & & 220 \\
\hline Colesterol (mg/dl) & 132 & 79 & 151 & & \\
\hline Triglicéridos (mg/dl) & 183 & & & & \\
\hline $\mathrm{PCR}(\mathrm{mg} / \mathrm{L})(<0,6)$ & & 21,3 & 12,7 & & 5,9 \\
\hline TSH (uUl/ml) & 1,9 & & & & \\
\hline
\end{tabular}

VHS: velocidad de eritrosedimentación; VCM: volumen corpuscular medio; LDH: deshidrogenasa láctica; PCR: proteína C reactiva; alc: alcalinas; SGOT: transaminasa oxaloacética; SGPT: transaminasa pirúvica; GGT: gamaglutamiltranspeptidasa; TSH: hormona tiroestimulante. 
vasos del cuello eran normales en la ecografía. En la angioresonancia el tejido periaórtico se reforzó con gadolinio concluyéndose que era un tejido inflamatorio-fibroso. La estenosis de AMS era crítica; las dos arterias renales izquierdas y el tronco celíaco presentaban estenosis de $70 \%$ y la arteria renal derecha y mesentérica inferior, estenosis de $50 \%$. Los senos renales y áreas perinéfricas estaban ocupados por el tejido que envolvía a la aorta. Se instaló stents en AMS y en ambas arterias renales, mejorando la perfusión (Figura 1). El radiólogo planteó ECD. El cintigrama óseo fue compatible con dicho diagnóstico al mostrar un aumento de captación en fémures y tibias (Figura 2). Se inició tratamiento con prednisona $60 \mathrm{mg} /$ día y metotrexato $10 \mathrm{mg}$ semanales, con mejoría sintomática por lo que se redujo en forma gradual la dosis de corticoides hasta $10 \mathrm{mg}$. Tres meses después (marzo de 2008) fue hospitalizado por neumonía y tuvo una buena respuesta al tratamiento antibiótico. A los 12 meses del diagnóstico (diciembre de 2008) y estando el paciente prácticamente asintomático, salvo edema de piernas atribuido al uso de anagrelide, persistía anémico y con leucocitosis (Tabla 1). Un scanner mostró aumento del grosor del tejido periaórtico tanto en aorta ascendente como descendente y prolongación hasta el inicio de arterias ilíacas primitivas. A los 18 meses (julio de 2009), por dolor en rodillas se tomó radiografías que mostraron osteoesclerosis en fémures y tibias en la misma localización que las alteraciones del cintigrama óseo y calcificaciones del cartílago compatibles con condrocalcinosis (Figura 2). Un nuevo scanner, mostró persistencia de los hallazgos previos y aumento $(70 \%)$ en la estenosis de la arteria mesentérica inferior. A 28 meses del diagnóstico (abril de 2010), el paciente comenzó a presentar signos de insuficiencia cardiaca congestiva. El scanner mostró acentuación del tejido perirrenal, engrosamiento de las pleuras bibasales y aumento en la cantidad de líquido en el pericardio. El ecocardiograma mostró un gran derrame pericárdico con signos iniciales de taponamiento y superficie pericárdica irregular sugerente de infiltración tumoral. El electrocardiograma mostró bajo voltaje. Fue hospitalizado efectuándose una ventana pleuro-pericárdica. Durante la operación se encontró el pericardio a tensión drenando 1.200 $\mathrm{ml}$ de un líquido amarillo pardusco. El pericardio parietal era de aspecto normal y el visceral estaba infiltrado difusamente por un tejido duro. El líquido pericárdico tenía abundantes histiocitos al igual que el tejido pericárdico parietal resecado, que tenía infiltración por células de citoplasma granular y espumoso y el análisis inmunohistoquímico confirmó que dichas células correspondían

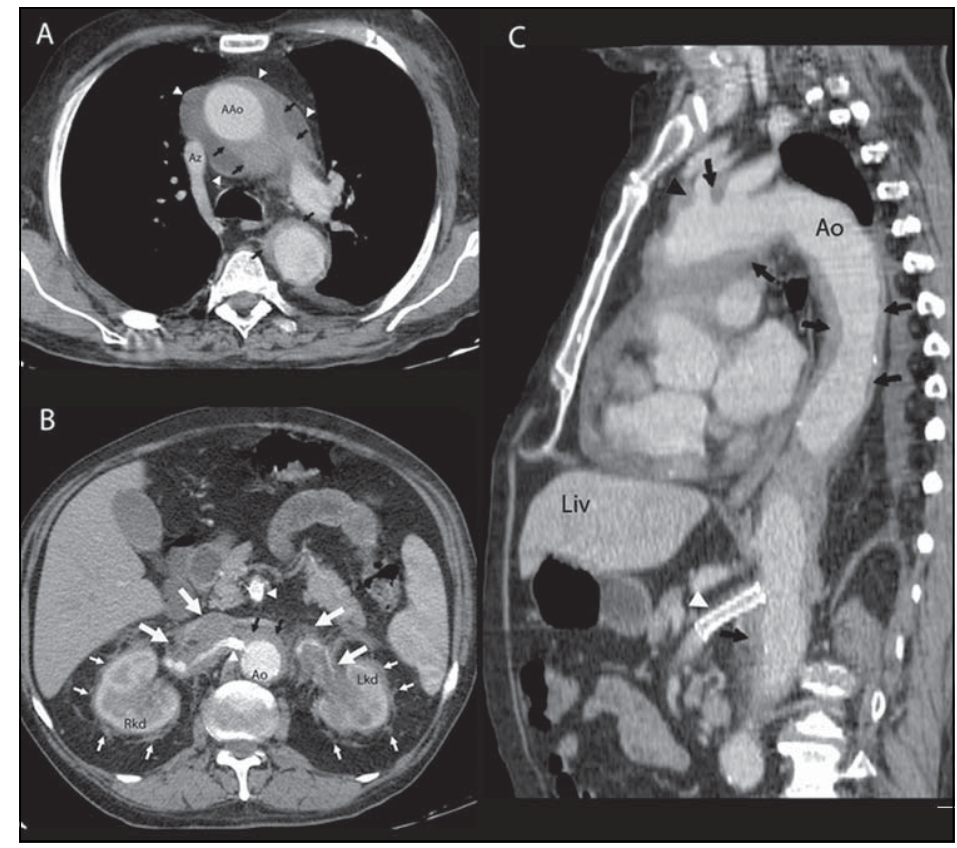

Figura 1. TC con contraste EV. Imágenes axiales (A y B ) y de reconstrucción sagital oblicua (C) que muestran presencia de un tejido de densidad de partes blandas con realce a nivel periaórtico (flechas negras pequeñas), que compromete tanto la aorta torácica y abdominal (Ao). También este tejido se extiende y engloba el tercio proximal de los troncos arteriales supraaórticos (cabeza de flecha negra). Engloba las estructuras vasculares de ambos hilios renales (flechas blancas), hasta ambos senos renales, con obliteración de la grasa. Es evidente un tejido denso y engrosamiento de los septos perirrenales (de Kunin), dando un aspecto denominado como "riñones peludos" (flechas blancas pequeñas), bastante característico de esta afección. Existe además distensión de recesos pericárdicos superiores a nivel mediastínico, con discreto engrosamiento pericárdico (cabezas de flechas blancas en A) y derrame pericárdico. Observe presencia de stents en tercio proximal de la arteria mesentérica superior y tercio proximal de arteria renal derecha (cabezas de flechas blancas en B y C). Mínimo derrame pleural izquierdo. Aorta torácica ascendente (AAo); Vena ácigos (Az); hígado (Liv); Riñón derecho (Rkd); Riñón izquierdo (Lkd). 


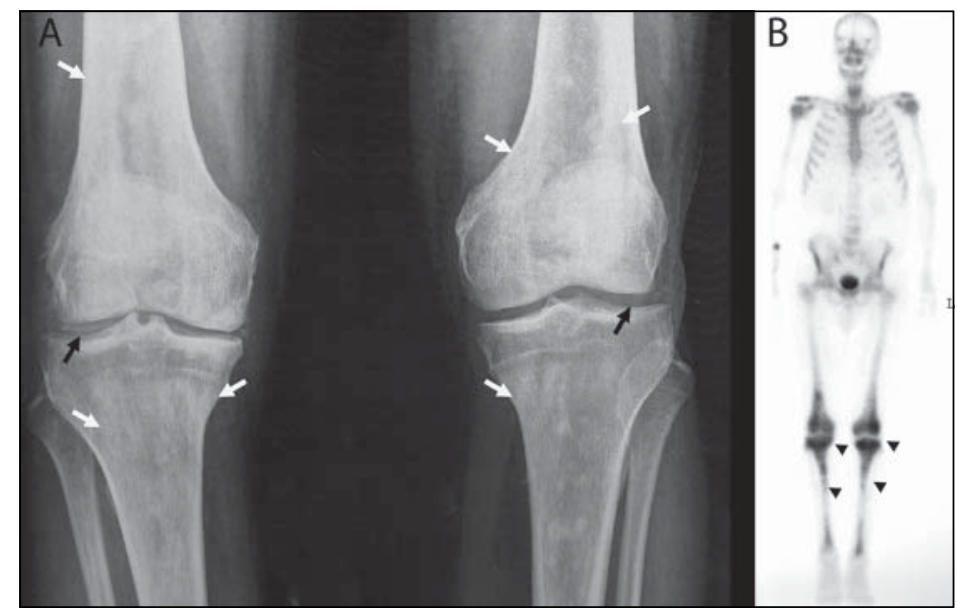

Figura 2. Rx de ambas rodillas frente $(\mathbf{A})$. Presencia de osteoesclerosis heterogénea, simétrica y bilateral, con mayor compromiso de región vecina a ambas rodillas (flechas blancas). Como hallazgo se evidencia presencia de condrocalcinosis, a predominio del compartimiento lateral de rodilla derecha (flechas negras). Cintigrama óseo (B). Aumento de la captación del radiotrazador, predominantemente en región vecina a ambas rodillas (cabezas de flechas).

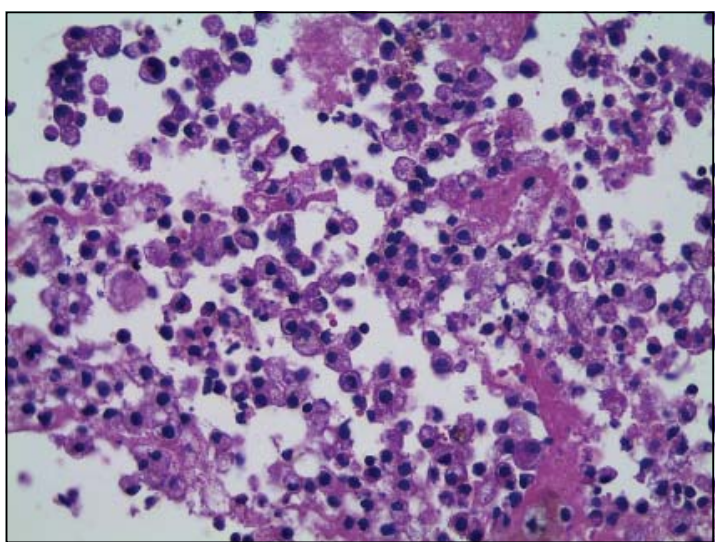

Figura 3. Histiocitos en líquido pericárdico obtenido durante la operación.

a histiocitos, CD68 (+), CD1a (-) y proteína S100 (-), confirmando la ECD (Figura 3). El paciente presentó clara mejoría de la sintomatología posterior al procedimiento.

\section{Discusión}

El compromiso cardiovascular en la ECD es frecuente. Se puede observar una aorta cubierta por una capa hasta en $56 \%$ de los pacientes con scanner o $\mathrm{RNM}^{1,6-8}$ cuya extensión puede abarcar desde la porción ascendente hasta la bifurcación iliaca afectando sus ramas y el mediastino. En la mitad de los casos el compromiso aórtico es global, en los restantes está limitado a la aorta torácica o abdominal en forma aislada ${ }^{1}$. Esta capa de tejido xantogranulomatoso puede infiltrar el retroperitoneo, produciendo estenosis de las arterias renales e hipertensión renovascular ${ }^{1}$. En este paciente se encontró estenosis de ambas arterias renales, que si bien no empeoraron su hipertensión requirieron angioplastia con stents. También, la fibrosis retroperitoneal (FRP) puede comprometer uréteres originando hidronefrosis e insuficiencia renal ${ }^{9}$. Un hallazgo característico es la infiltración de la grasa perirrenal originando "riñones peludos" (Figura 1) como se encontró en este paciente ${ }^{1,10}$. Otros hallazgos frecuentes son la afectación de arteria mesentérica superior-pudiendo provocar isquemia intestinal ${ }^{2}$, tronco celíaco y con menor frecuencia la arteria hepática y mesenterio ${ }^{1}$. En este paciente se encontró una estenosis crítica de AMS, asintomática, que requirió la colocación de un stent.

El pericardio frecuentemente es infiltrado originando un derrame que puede llegar al taponamiento ${ }^{1,11}$. En este paciente, existía un derrame pericárdico leve al diagnóstico que a pesar de la terapia con esteroides y metotrexato aumentó después del segundo año de evolución hasta originar insuficiencia cardiaca con signos de taponamiento cardiaco inicial. También el miocardio puede ser infiltrado produciendo un pseudotumor en aurícula derecha o afectación del ventrículo derecho, septum interauricular, vena cava superior, sulcus aurículo-ventricular, arterias coronarias (existen comunicaciones de infartos), seno coronario y arterias pulmonares ${ }^{1,6,8,12-14}$. Puede existir insufi- 
ciencia aortica o insuficiencia mitral y durante los recambios valvulares se ha encontrado infiltración por histiocitos ${ }^{1}$. En este paciente se encontró signos ecográficos de insuficiencia aórtica desde el momento del diagnóstico, los cuales no progresaron. La presencia de insuficiencia cardiaca es un hallazgo común, a veces originada por una cardiopatía restrictiva y constrictiva como ocurrió con este paciente ${ }^{1}$.

Los exámenes de laboratorio de la ECD son los propios de una enfermedad inflamatoria crónica, existiendo anemia, leucocitosis, trombocitosis, velocidad de sedimentación y proteína $\mathrm{C}$ reactiva elevada ${ }^{1}$, como los presentó este paciente (Tabla 1) y también puede existir elevación de fosfatasas alcalinas ${ }^{2}$.

El diagnóstico diferencial de la ECD cardiovascular incluye: linfomas, angiosarcoma cardiaco, fibrosis retroperitoneal (FRP) y enfermedad de Takayasu. En esta última el compromiso vascular afecta desde adventicia a la íntima, en cambio, en ECD el compromiso es sólo de la adventicia y tejidos periaórticos. En la FRP el compromiso vascular no es circunferencial, respetando la pared posterior de aorta ${ }^{1}$.

El diagnóstico histológico de ECD se hace con biopsia ósea o por punción percutánea del tejido perirrenal ${ }^{1}$, que revela fibrosis, inflamación e infiltración por macrófagos cargados de grasa o histiocitos espumosos cuyas tinciones son característicamente CD68 (+), CDla (-) y proteína S-100 (- $)^{2,14}$. En este paciente el diagnóstico se confirmó con el análisis histológico y citológico del material pericárdico obtenido en la operación.

La ECD no tiene un tratamiento establecido. Se han empleado corticoides, quimioterapia, radioterapia, inmunosupresores, interferón alpha, talidomida, bifosfonatos, imatinib y trasplante de células troncales hematopoyéticas; con resultados variables $^{1,2,15}$. En este paciente, la terapia con corticoides y metotrexato probablemente enlenteció la progresión de la enfermedad pero no la detuvo. En la publicación que reunió el mayor número de casos de ECD con compromiso cardiovascular la mortalidad fue $60 \%{ }^{1}$. Un tercio de los fallecimientos ocurrió por causa cardiovascular, a menudo por insuficiencia cardiaca ${ }^{1}$. El pronóstico es variable y empeora cuando existe compromiso del sistema nervioso y/o cardiovascular. La duración de la sobrevida fue 19-32 meses desde la fecha del diagnóstico ${ }^{1,2}$.
El derrame pericárdico no es una situación infrecuente en la práctica clínica y puede originarse por el compromiso pericárdico de diversas etiologías: infecciones virales o bacterianas, tuberculosis, posteriores a un infarto miocárdico o cirugía cardiaca, traumatismos torácicos, infecciones por HIV, idiopáticas, radiación mediastínica, enfermedades colágeno-vasculares, insuficiencia renal crónica avanzada o diálisis, drogas, mixedema y neoplasias malignas. De estas últimas las más frecuentes son el cáncer pulmonar y mamario, enfermedad de Hodgkin y los mesoteliomas. En una serie de 75 pacientes ingresados a un hospital terciario por un derrame pericárdico de causa no clara, $27 \%$ fue originado en infecciones, $23 \%$ por neoplasias malignas, $14 \%$ por radiación, $12 \%$ por enfermedades autoinmunes, $12 \%$ por insuficiencia renal crónica y en $7 \%$ su causa no pudo establecerse $^{17}$.

En los pacientes con derrame y engrosamiento pericárdico, particularmente cuando son añosos, es común que se sospeche una etiología neoplásica y que se soliciten exámenes de imágenes para localizar el tumor primario, si este no es clínicamente evidente y un cintigrama óseo para conocer si hay metástasis esqueléticas. El encontrar un manguito alrededor de la aorta torácica y/o abdominal, engrosamiento del tejido perirenal o un aumento simétrico de captación en fémures y tibias en un cintigrama óseo, debe hacer sospechar el diagnóstico de una ECD.

Si bien la ECD es una enfermedad rara, creemos que es una buena idea incorporar la solicitud de radiografías de ambos fémures y tibias en el estudio de los pacientes con derrame y engrosamiento pericárdico de causa desconocida, ya que el encontrar una osteosclerosis simétrica en estos huesos es patognomónico de esta enfermedad.

\section{Referencias}

1. Haroche J, Amoura Z, Dion E, Wechsler B, CostedoatChalumeau N, Cacoub P, et al. Cardiovascular involvement, an overlooked feature of Erdheim-Chester disease. Medicine (Baltimore) 2004: 83: 371-92.

2. Veyssier-Belot C, Cacoub P, Caparros-Lefebvre D, Wechsler J, Brun B, Remy M, et al. Erdheim-Chester disease: clinical and radiologic characteristics of 59 cases. Medicine (Baltimore) 1996; 75: 157-69.

3. Drier A, Haroche J, Savatovsky J, Godenèche G, Dor- 
mont D, Chiras J, et al. Cerebral, facial, and orbital involvement in Erdheim-Chester disease: CT and MR imaging findings. Radiology 2010; 255: 586-94.

4. Arnaud L, Pierre I, Beigelman C, Capron F, Brun AL, Rigolet A, et al. Pulmonary involvement in ErdheimChester disease: A single center experience of 34 patients and review of the literature. Arthritis Rheum 2010; Jul 26 [Epub ahead of print].

5. Alfieri A, Gazzeri R, Galarza M, Neroni M. Surgical treatment of intracranial Erdheim-Chester disease. J Clin Neurosci 2010; Sep 13 [Epub ahead of print].

6. Haroche J, Cluzel P, Toledano D, Montalescot G, Touitou D, Grenier P, et al. Cardiac involvement in ErdheimChester disease. Magnetic resonance and computed tomographic scan imaging in a monocentric series of 37 patients. Circulation 2009; 119: e597-8.

7. Serratrice J, Granel B, De Roux C, Pellissier JF, Swiader L, Bartoli JM, et al. "Coated aorta": a new sign of ErdheimChester disease. J Rheumatol 2000; 27: 1550-3.

8. Brun AL, Touitou-Gottenberg D, Haroche J, Toledano D, Cluzel P, Beigelman-Aubry C, et al. Erdheim-Chester disease: CT findings of thoracic involvement. Eur Radiol 2010; Jun 20 [Epub ahead of print].

9. Sánchez JE, Mora C, Macia M, Navarro JF. ErdheimChester disease as cause of end-stage renal failure: a case report and review of the literature. Int Urol Nephrol 2010; Mar 16 [Epub ahead of print].

10. Vaglio A, Corradi D, Maestri R, Callegari S, Buzio C,
Salvarani C. Pericarditis heralding Erdheim-Chester disease. Circulation 2008; 118: e511-2.

11. Gupta A, Kelly B, McGuigan JE. Erdheim-Chester disease with prominent pericardial involvement: clinical, radiologic, and histologic findings. Am J Sci 2002; 324: 96-100.

12. Elgeti T, Schlegl M, Nitardy A, Kivelitz DE, Stockburger M. Magnetic resonance imaging guiding pacemaker implantation for severe sinus node dysfunction due to cardiac involvement in Erdheim-Chester disease. Circulation 2007; 115: e412-4.

13. Granier M, Micheau A, Serre I. A rare cause of cardiac tumour: an Erdheim-Chester disease with cardiac involvement co-existing with an intracerebral Langerhans cell histiocytosis. Eur Heart J 2008; 29: 1929.

14. Bassou D, El Kharras A, Amezyane T, En Nouali H, Elbaaj M, Benameur M, et al. Cardiac Erdheim-Chester. Intern Med 2009; 48: 83-84.

15. Dickson BC, Pethe V, Chung CT, Howarth DJ, Bilbao JM, Fornasier VL, et al. Systemic Erdheim-Chester disease. Virchows Arch 2008; 452: 221-7.

16. Boissel N, Wechsler B, Lebold V. Treatment of refractory Erdheim-Chester disease with double autologous hematopoietic stem-cell transplantation. Ann Intern Med 2001; 135: 844-5.

17. Corey GR, Campbell PT, Van Trigt P, Kenney RT, O'Connor CM, Sheikh KH, et al. Etiology of large pericardial effusions. Am J Med 1993; 95: 209-13. 